\title{
AVALIAÇÃO, QUALIDADE E EQUIDADE
}

\author{
Carlinda Leite* \\ Preciosa Fernandes $* *$
}

Recebido: 5 mar. 2014

Aprovado: 30 maio 2014

*Universidade do Porto, Faculdade de Psicologia e de Ciências da Educação, Porto, Portugal. Contato com a autora:E-mail: carlinda@fpce.up.pt

**Universidade do Porto, Faculdade de Psicologia e de Ciências da Educação, Porto, Portugal. Contato com a autora: Email: preciosa@fpce.up.pt

Resumo: O artigo, focado na avaliação da aprendizagem dos ensinos fundamental, médio e superior, tem como objetivo debater possibilidades e limites da avaliação de aprendizagem constituir um meio para promover uma educação de qualidade que viabilize o princípio de justiça social. Partindo de uma análise de políticas internacionais que têm associado a avaliação à institucionalização de uma educação de qualidade, o artigo dá conta de princípios e caraterísticas que marcam os discursos académicos e legais, sobre a avaliação da aprendizagem, em Portugal. Com base nesta caraterização, são identificadas proximidades e distâncias entre esses discursos e práticas de avaliação. $\mathrm{O}$ artigo termina com uma reflexão sobre o contributo da avaliação da aprendizagem para uma educação de qualidade que cumpra requisitos de equidade e justiça social.

Palavras-chave: Avaliação da aprendizagem. Qualidade. Equidade. Ensinos fundamental, médio e superior.

\section{EVALUATION, QUALITY AND EQUITY}

Abstract: This article focuses on basic, secondary and higher education learning evaluation. Its main objective is to debate the possibilities and limitations of how the learning evaluation can be a way to improve education quality that promotes social justice. Starting with an analysis of the international policies that associate evaluation to quality education, the article defines principles and characteristics that mark academic and legal debates pertaining to learning evaluation in Portugal. Based on this characterisation, similarities and differences, between these debates and evaluation practices, have been identified. The article ends with a reflection about the important role that learning evaluation play in a quality education that meets requisites for equity and social justice.

Key words: Learning evaluation. Education quality. Equity. Elementary higher education. 


\section{INTRODUÇÃO}

Foi com a primeira Lei de Bases do Sistema Educativo Português (Lei $n^{0}$ 46/1986) que alguns dos ideais da revolução de abril de 1974, tais como a igualdade de oportunidades de acesso e de sucesso escolares e a responsabilização do sistema por concretizar princípios de uma educação inclusiva e democrática, passaram a ter visibilidade legal. A acompanhar esta orientação, $o$ discurso político passou a enfatizar o sucesso escolar dos alunos e a legislação daí decorrente colocou a tónica no recurso a processos de avaliação formativa e de apoio a alunos com dificuldades de aprendizagem. Apesar disso, de um modo geral, e talvez pelo facto do ensino superior gozar de maior autonomia, esta característica discursiva esteve quase só presente nos ensinos fundamental e médio. Foi já no final do século XX que a Conferência Mundial sobre Educação Superior no século XXI, convocada pela UNESCO e celebrada em Paris, em Outubro de 1998 (UNESCO, 1998), trouxe este discurso para este nível de ensino, afirmando que as instituições devem formar os estudantes para que estes sejam bons cidadãos e não apenas poços de ciência. Ou seja, veiculou um discurso fundado em uma formação ampla e não apenas restrita à obtenção de conhecimentos. Com a chegada ao século XXI, e para todos os níveis de ensino, os discursos políticos passaram a associar a procura de sucesso educativo a princípios de qualidade e a difundir a ideia de que a avaliação, quer das aprendizagens, quer das instituições, constituiria o meio de a concretizar. É no quadro destas orientações políticas e das conceções que as suportam que se situa este artigo. Focado na avaliação da aprendizagem dos alunos, o seu objetivo é promover um debate sobre possibilidades e limites da avaliação poder constituir um meio de promover uma educação de qualidade, respeitando princípios de equidade.

Para concretizar este objetivo, o texto segue uma estrutura que pretende responder às seguintes perguntas: Como tem sido percecionada a qualidade $\mathrm{e}$ que relação tem com os processos de avaliação? Que princípios e caraterísticas têm orientado a avaliação da aprendizagem em Portugal? Como pode a avaliação constituir um dispositivo que promova a equidade?

\section{A AVALIAÇÃO NA SUA RELAÇÃO COM A QUALIDADE}

O discurso da qualidade e o da avaliação enquanto meio de monitorização dessa qualidade têm vindo a ocupar as agendas das políticas educacionais (LEITE, 2012) de vários países. No caso de Portugal, e outros países europeus, 
liga-os o compromisso de se envolverem na criação do Espaço Europeu do Ensino Superior (EEES) com o incentivo de promover a cooperação europeia na garantia da qualidade através do desenvolvimento de critérios e metodologias comparáveis. Ou seja, e como é afirmado por Santos (2011, p. 2),

as modificações radicais que se verificaram na envolvente do ensino superior no último quartel do séc. XX tiveram, entre outros efeitos, o de levantar preocupações sérias em relação à qualidade, tanto no interior das instituições como por parte da sociedade, colocando a problemática da avaliação, de uma forma incontornável, na agenda do ensino superior.

No entanto, e convocando Dias Sobrinho (2012), a compreensão das políticas de qualidade que se instalaram nos sistemas educacionais implica ter em consideração as políticas de globalização e os seus efeitos, nomeadamente, no caso do ensino superior, ao nível da missão das instituições. De facto, no que a este nível de ensino diz respeito, a lógica de mercado tem constituído uma marca, principalmente a partir do reconhecimento, na Estratégia de Lisboa (2000), do conhecimento como um bem comercializável. Foi nesta linha que foi fixado como objetivo estratégico constituir, até 2010, uma economia baseada no conhecimento mais competitivo do mundo, capaz de garantir um crescimento económico sustentável. É nesta lógica que Amaral et al. (2002) afirmam que o ensino passou a ser conduzido pela mão do mercado e que Robertson (2009) refere que a situação de desvantagem da Europa face às economias dos países emergentes justificou a criação de um projeto político e económico baseado no conhecimento.

O Processo e Bolonha, que envolve vários países europeus, foi delineado no quadro destes objetivos na intenção de atrair estudantes de países emergentes que até aí procuravam os Estados Unidos da América. Ou seja, e reforçando o que já atrás foi afirmado, a educação foi "sendo transformada num bem de consumo comercializado internacionalmente" (ALTABACH, 2002, p. 58) assumindo as Universidades o "estatuto de empresa transnacional" (READINGS, 2003, p. 12).

Em consequência destes novos compromissos, a missão das instituições de ensino superior passou a viver na tensão decorrente de lógicas de mercado, a par de um estreitamento de relações com a sociedade (MAGALHÃES, 2004) e as questões sociais. Aliás, este último aspeto, em Portugal, ganhou alguma visibilidade passando as atividades de extensão a serem claramente enunciadas como uma das quatro dimensões do exercício da docência dos professores do ensino superior e a serem tidas em conta na sua avaliação (Decreto-lei no 74/2006). 
Apesar disso, nesta lógica empresarial, mais importante do que a relação com as comunidades locais e o envolvimento dos professores na docência passaram a ser os critérios que permitem às instituições de ensino superior ocupar um bom lugar nos rankings internacionais. Ora, sendo o lugar nesses rankings estabelecido pela avaliação focada em critérios internacionalmente definidos, eles são determinantes nos sentidos em que é reconhecida a qualidade, isto é, o conceito de qualidade passou a ser comandado por decisões e diretivas internacionais (ROBERTSON, 2009; LIMA, 2012). No caso dos países europeus que aderiram ao Processo de Bolonha, em reunião de Ministros da Educação realizada em Berlim em 2003, foi definida a necessidade de serem desenvolvidos critérios e metodologias de garantia da qualidade mutuamente partilhados pelos diversos parceiros. Nesse sentido, no comunicado resultante dessa reunião foi definido que os sistemas nacionais de garantia da qualidade deviam incluir uma avaliação de programas ou instituições compreendendo uma avaliação interna e uma avaliação externa, um sistema de acreditação ou de certificação e a participação e cooperação internacional. Por outro lado, nessa mesma reunião a ENQA (constituída pelo European Network for Quality Assurance in Higher Education e integrando representantes de agências nacionais ou regionais de avaliação e representantes dos governos) foi mandata para estabelecer padrões, procedimentos e orientações sobre a garantia da qualidade, trabalho esse que foi concretizado nos Standards and Guidelines for Quality Assurance in the European Higher Education Area (ESG), aprovados na reunião de Ministros, em 2005, em Bergen.

O que aconteceu nos ensinos fundamental e médio não é também muito distinto do que ocorreu no ensino superior, nomeadamente no que diz respeito ao paradigma da qualidade e da justificação do recurso à avaliação enquanto meio de a garantir. São disso exemplo recomendações europeias que apontam para a institucionalização de sistemas de garantia da qualidade com recurso à avaliação, de modo a tornar as escolas mais eficazes (COMMISSION OF THE EUROPEAN COMMUNITIES, 2001), ou a Recomendação do Parlamento Europeu e do Conselho (de 12 de fevereiro de 2001) sobre a cooperação europeia em matéria de avaliação da qualidade dos ensinos fundamental e médio, e que dá relevo à necessidade de desenvolver processos de avaliação de escolas. É no quadro desta orientação para a qualidade e da avaliação como forma de a implementar e garantir que a OCDE (2012) tem apontado os procedimentos avaliativos quer como meio de prestação de contas, face ao investimento que é feito na educação, quer como meio de promover a melhoria da ação educacional e das aprendizagens dos alunos. 
Como tem sido reconhecido, o conceito de qualidade é historicamente situado, isto é, "vincula-se às demandas e exigências de um dado processo histórico" (DOURADO; OLIVEIRA, 2009, p. 203), o que justifica que actualmente a qualidade seja associada, no caso dos ensinos fundamental e médio, a resultados escolares elevados dos alunos nos exames nacionais e, no caso do ensino superior, uma formação adequada às exigências do mercado. É contra estes sentidos de qualidade que se têm insurgido alguns dos discursos académicos, nomeadamente quando o associam ao termo social querendo com isso significar a superação de uma mera aquisição de informações ou de resultados obtidos por exames ou provas nacionais. Ao contrário, estes discursos académicos que apontam para a importância da qualidade social, atribuem a este conceito uma "forte componente ético-social marcada pelo direito do cidadão a ter direitos" (MOROSINI, 2006, p. 469), isto é, consideram que a qualidade existe "só quando uma instituição alia em alto grau as suas funções científico-formativas com as realidades concretas da sociedade na qual está inserida, ou seja, quando conhecimento e formação se enlaçam com os projectos pessoais e sociais de construção da cidadania pública" (DIAS SOBRINHO, 2012, p. 615).

\section{A AVALIAÇÃO DA APRENDIZAGEM EM PORTUGAL}

Na sequência do que até aqui temos referido, em Portugal, a avaliação da aprendizagem dos alunos tem vindo a constituir objeto de um interesse cada vez maior, quer dos decisores políticos, quer dos académicos (ver a este propósito FERNANDES, 2004, 2009). Tanto nos discursos políticos como nos académicos, a tónica tem sido colocada na afirmação de princípios precursores de uma avaliação formativa, isto é, de uma avaliação ao serviço da aprendizagem. No entanto, estudos realizados mostram que as práticas avaliativas, podendo na sua origem ter intencionalidades formativas, assumem essencialmente caraterísticas de natureza eminentemente sumativa (quer se trate de situações relacionadas com o ensino médio e fundamental (BARREIRA; PINTO, 2005; CORTESÃO, 2002; MARINHO; LEITE; FERNANDES, 2013), quer com o ensino superior (FERREIRA, 2013; FERNANDES, 2010; FIRMINO, 2013, FIRMINO; LEITE, 2014). Também a nível do discurso oficial se tem assistido a um Zig-Zag legislativo (BARREIRA; PINTO, 2005), caraterizado por orientações que apelam para princípios de avaliação formativa e, simultaneamente, para a garantia da qualidade e do rigor. É esta trajetória que apresentamos no ponto seguinte deste artigo, situando-nos no período 
pós $1^{\text {a }}$ Lei de Bases do Sistema Educativo Português (Lei no $46 / 86$ de 14 de outubro) até às orientações decorrentes do Processo de Bolonha (PB) iniciadas em Portugal em 2007 e desde aí em curso.

\subsection{Princípios e Caraterísticas que têm Orientado a Avaliação nos Discursos Académicos e Políticos}

O final da década de oitenta e princípios da década de noventa do século XX representam, em Portugal, um período relevante na institucionalização de uma política de incentivo à avaliação formativa. Nesse contexto, no caso dos ensinos fundamental, o Despacho Normativo ${ }^{\circ}$ 98-A/92, de 20 de junho, determina a avaliação formativa como modalidade a ser seguida no ensino fundamental. Sustentava-se, então, uma avaliação contínua com recurso a informações de vária ordem que permitissem ao professor, acompanhar, e regular, todo o processo de ensino-aprendizagem dos alunos e, assim, ajuizar sobre os seus progressos nas aprendizagens. Igualmente previa fornecer aos alunos e aos encarregados de educação informações sobre os processos de ensino-aprendizagem seguidos e os efeitos verificados nos alunos. Como nesse diploma legal é enunciado, a avaliação formativa constitui a "principal modalidade de avaliação do ensino básico que se destina a informar o aluno, o seu encarregado de educação, os professores e outros intervenientes sobre a qualidade do processo educativo e de aprendizagem" (n ${ }^{\circ} 18$, Despacho 98 A/92). Tratou-se de um diploma marcante que contribuiu para fazer uma rutura da avaliação restrita à dimensão classificatória e de ampliar o debate académico que a associa a dispositivo promotor da aprendizagem (CORTESÃO, 1993; LEITE, 2001; FERNANDES, 1994, 1997; PACHECO, 1994; LEITE; FERNANDES, 2002). Como sublinharam estas últimas autoras aquele Despacho normativo "propunha já uma avaliação predominantemente formativa que substituísse a lógica da seleção, que aceita a existência do insucesso escolar, pela lógica do sucesso para todos" (LEITE; FERNANDES, 2002, p. 77). A avaliação formativa era então entendida como "um conjunto de práticas variadas que se integram no processo de ensino/ aprendizagem e que procuram contribuir para que os alunos se apropriem melhor das aprendizagens curricularmente estabelecidas como importantes" (CORTESÃO, 1993, p. 12).

Numa linha de concordância, Pacheco (1994, p. 101) argumentava, à altura, que "na escolaridade obrigatória não há, com certeza, outra modalidade que melhor corresponda aos propósitos de uma educação para todos e de uma pedagogia de sucesso" como a avaliação formativa. Perspetivada como uma 
complexa modalidade de avaliação, a sua concretização era também vista como requerendo, por parte dos professores, uma compreensão clara dos seus fundamentos. Como sublinha Fernandes (2006, p. 21), "mudar e melhorar práticas de avaliação formativa implica que o seu significado seja claro para os professores, tanto mais que são muito fortes e complexas as suas relações com os processos de ensino e de aprendizagem". Talvez tenha sido por isso que, em 1994, o Ministério da Educação tenha reconhecido a importância de aditar ao diploma legal que regulamentava esta conceção de avaliação elementos relacionados com uma maior equidade e rigor nos processos avaliativos (Despacho Normativo $n^{\circ}$ 644-A de 15 de setembro de 1994) determinando a uniformização de critérios de retenção dos alunos, eventualmente na intenção de intervir ao nível das disparidades que a esse nível existiam. Todavia, este mesmo Despacho introduziu também as provas globais no $9^{\circ}$ ano de escolaridade, o que parece sugerir um 'passo atrás' em relação ao enaltecimento da avaliação formativa expresso na legislação anterior.

Este foi um aspeto a que não escapou o olhar de académicos. Machado (1994, p. 45) considerou, à data, que os acertos feitos ao Despacho 98-A/92 representavam "[...] mudanças estruturais que podiam atingir ou perverter vectores fundamentais do modelo e, por isso, a sua filosofia global". Em proximidade com esta visão, Afonso (1998, p. 261) refere que aquelas alterações "denotam uma tendência muito nítida para um retorno a um modelo de avaliação potencialmente mais seletivo e menos democrático". Argumenta este académico que essas mudanças introduzidas parecem apenas ter tido a intenção de "repor alguns dispositivos que (tinham) como efeito atender às pressões e dar uma satisfação às críticas procedentes de certos setores sociais, sem nada resolver em concreto" (AFONSO, 1998, p. 261).

Nesta leitura diacrónica, as alterações curriculares ocorridas no ensino fundamental ${ }^{1}$ e médio ${ }^{2}$, no final do século XX e inícios do século XXI, em Portugal, lançaram novos desafios às escolas e aos professores, quer no que respeita ao entendimento do currículo e aos processos do seu desenvolvimento, quer relativamente à avaliação da aprendizagem. Assiste-se neste período à implementação de processos de Reorganização Curricular do Ensino Básico/fundamental e de Revisão do Ensino Secundário/médio. Neste contexto de reforma curricular e, simultaneamente, no quadro do desenvolvimento da autonomia das Escolas ${ }^{3}$ é

1 As mudanças curriculares ocorridas neste período ao nível do ensino fundamental foram regulamentadas pelo decreto-lei 6/2001, de 18 de janeiro.

2 As mudanças curriculares ocorridas neste período ao nível do ensino fundamental foram regulamentadas pelo decreto-lei 74/2004, de 26 de março.

3 O decreto-lei 115A/98 de 4 de maio define, à data, o regime de autonomia, administração e gestão dos 
estabelecido que o currículo nacional deve ser adequado ao contexto de cada escola, devendo, para isso, ser construído

um projecto curricular de escola, concebido, aprovado e avaliado pelos respectivos órgãos de administração e gestão, o qual deverá ser desenvolvido, em função do contexto de cada turma, num projecto curricular de turma, concebido, aprovado e avaliado pelo professor titular de turma ou pelo conselho de turma, consoante os ciclos. (Preâmbulo Decreto lei nº. 6/2001).

Os Projetos curriculares configuram assim "modos de favorecer a criação de dinâmicas de envolvimento e de co-responsabilização pelo acto de ensinar e de aprender e modos de promover a adequação do currículo nacional aos contextos onde vais ser vivido" (LEITE; FERNANDES, 2002, p. 77). No quadro desta mudança, o currículo e a avaliação são reconhecidos pela administração educacional como componentes integradas de um mesmo sistema e não como sistemas separados. É proclamado pelo então Diretor Geral da Educação Básica que "a avaliação envolve interpretação, reflexão, informação e decisão sobre os processos de ensino e aprendizagem, tendo como principal função ajudar a promover ou melhorar a formação dos alunos" (ABRANTES, 2002, p. 10).

Foi neste enquadramento que o discurso político reiterou que a avaliação formativa é a principal modalidade de avaliação das aprendizagens dos alunos (Despacho 30/2001 de 19 de julho). Numa visão mais progressista da avaliação formativa, e enquanto dimensão integrada do currículo, este diploma legal sustenta a importância de se atender a informações de caráter diverso, recolhidas, através de diferentes meios e instrumentos, numa dinâmica processual, e mais prolongada no tempo, e interligada com as situações e contextos reais. A separação entre avaliação formativa e sumativa parece, assim, ficar mais atenuada, sugerindo até que a avaliação sumativa seja investida de um sentido formativo, ao prever-se a possibilidade de reajustamentos, pelo conselho de turma, nos resultados dos alunos, com repercussões ao nível da melhoria dos processos de ensino-aprendizagem.

O posicionamento de alguns académicos sobre estas orientações é de congratulação face à continuidade de uma política curricular e de avaliação que valoriza não apenas os resultados académicos mas também o desenvolvimento de outras competências transversais potenciadoras da formação global dos jovens. Com efeito, são vários os académicos que se pronunciam positivamente face ao discurso oficial (ALONSO, 2002; FERNANDES, 2002; LEITE, 2002a;

estabelecimentos de educação pré-escolar e dos ensinos básico (fundamental) e secundário (médio). 
PACHECO, 2002; PERALTA, 2002; SANTOS, 2002) e são muitas as publicações sobre a avaliação da aprendizagem produzidas nesse período (ALVES, 2004, CUNHA, 2001; LEITE; FERNANDES, 2002; FERNANDES, 2004, 2006, entre outros). A tendência destes discursos aponta para uma ressignificação dos sentidos de avaliação formativa reconhecendo-se que esta tem de se configurar em processos sempre contextualizados às caraterísticas dos sujeitos e das situações em que estão envolvidos/inseridos. A avaliação é, neste sentido, encarada como uma prática social contextualizada.

Como é evidente, estas considerações atribuem um importante papel ao professor na configuração de processos formativos mais ou menos ricos em experiências e, assim, potenciadores de aprendizagens significativas. Como sublinha Cortesão (2002, p. 41),

se a escola, os professores e o sistema admit(ir)em a possibilidade de que lhes cabe uma quota parte de responsabilidade no tipo de resultados obtidos pelos alunos e portanto do êxito ou sucesso que eles têm, então o modo como se orienta o processo educativo e a avaliação adquirem outros significados.

Isto para dizer que a avaliação formativa, embora continue a ser uma orientação perfilhada por muitos académicos, precisa ainda de ser apropriada nos princípios que a caraterizam para poder ser concretizada na prática (FERNANDES, 2009). Estudos recentes focados, quer no ensino fundamental (MARINHO; LEITE; FERNANDES, 2013), quer no ensino superior (FERREIRA, 2013; FIRMINO; LEITE, 2014) dão-nos conta da dificuldade de passar das intenções às práticas efetivas de avaliação formativa. $\mathrm{O}$ primeiro estudo entre outros aspetos, mostra que a avaliação formativa faz parte do domínio das intenções, imperando, sobremaneira, ao nível das práticas, uma cultura de testinite. Os segundos estudos, focados no ensino superior, concluem que "que as práticas de avaliação programadas são, sobretudo, de natureza sumativa, apesar de nalgumas unidades curriculares se encontrarem alguns elementos da prática da avaliação formativa" (FERREIRA, 2013, p, 685) e que "we are still faced with a certain continuity of the dominant pedagogical culture in which the teacher assesses with the objective of grading" (FIRMINO; LEITE, 2014, p. 12).

Retomando o fio da análise sobre os discursos legais que regulamentam a avaliação da aprendizagem em Portugal, remontamos ao ano 2005, e onde há que destacar o facto de, em 2005 (Despacho Normativo $n^{\circ} 1 / 2005$ ), ser introduzida uma visão segmentada da avaliação, ao prescrever-se a avaliação formativa e a diagnóstica como se de duas modalidades de avaliação se tratasse. A orientação 
antes proclamada, relativa à avaliação dos alunos e ao seu caráter dinâmico e continuado no tempo pode, à luz deste documento, ter-se perdido. Este foi, de facto, um diploma polémico, e que mereceu a atenção de muitos académicos, por causa das alterações introduzidas, pelo modo como chegou, inesperadamente, às escolas (LEITE; FERNANDES, 2004) e por representar uma regressão em termos dos princípios antes proclamados (BARREIRA; PINTO, 2005). A este nível, este diploma expressou a mudança na tónica do discurso, que deu ênfase aos conceitos de qualidade e de excelência académica, e veiculou o retorno aos exames nacionais no $9^{\circ}$ ano (Matemática e Língua Portuguesa). Num posicionamento crítico Barreira e Pinto (2005, p. 19) consideram que "o problema não é tanto os exames no final dos ciclos, isto é, um processo de validação social dos saberes, mas a crença confusional entre qualidade e avaliação". Neste sentido, estes autores consideram que o "modelo que se adota está próximo dos exames do século passado" (BARREIRA; PINTO, 2005, p. 19).

No que ao ensino superior diz respeito, e decorrente da adesão e adequação ao Processo de Bolonha, o discurso legal apontou para a necessidade de "transição de um sistema de ensino baseado na ideia de transmissão de conhecimento para um sistema baseado no desenvolvimento de competências" (Decreto-lei $n^{\circ} 74 / 2006$, de 24 de março). Este discurso, como é evidente, implica um paradigma educacional e curricular que está em linha com conceções de avaliação da aprendizagem de ordem formativa. No entanto, também a este nível, em legislação mais recente é veiculado um discurso que, de certo modo, pode representar um retrocesso, nomeadamente quando, a propósito deste paradigma, é afirmado: "É, porém, errado desvalorizar o conhecimento, ou artificialmente opô-lo à noção de 'competências', pelas quais deveria ser sempre englobado. O conhecimento, no entanto, é central ..." (Decreto-Lei ${ }^{\circ}$ 115/2013, de 7 de agosto).

Como se depreende da análise aqui realizada e focada nos discursos políticos veiculados pelos diplomas legais sobre a avaliação da aprendizagem, em Portugal, a Lei de Bases do Sistema Educativo (1986) apontou para princípios de avaliação formativa. Contudo, essa orientação tem convivido com outras modalidades designadamente: a avaliação sumativa extraordinária; a avaliação aferida; as provas de Português e Matemática de final de anos de conclusão do $2^{\circ}$ e do $3^{\circ}$ ciclo do ensino básico/fundamental; e os exames nacionais do ensino secundário/médio.

Nos últimos anos, este discurso político tem enfatizado a avaliação sumativa e reforçado a valorização dos exames como instrumentos importantes para se conhecer a qualidade das aprendizagens realizadas pelos alunos. Posicionando- 
-se em relação ao que tem sido determinado por estes diplomas legais, Fernandes (2005, p. 15) sustenta que

continuam a prevalecer modelos de avaliação pouco integrados no ensino e na aprendizagem, mais orientados para a atribuição de classificações do que para a análise do que os alunos sabem e fazem, para a compreensão das suas dificuldades e para a ajuda à sua superação.

Esta consideração é igualmente válida para o ensino superior. Decorridos oito anos da implementação do Processo de Bolonha em Portugal, estudos realizados revelam (FERNANDES, 2010; FIRMINO, 2013; FERREIRA, 2013; FIRMINO; LEITE, 2014) que os princípios de aprendizagem autónoma e, portanto, de auto-regulação dos estudantes pelos seus processos de formação continuam a estar mais nos enunciados do que nas práticas.

\section{PARA UMA AVALIAÇÃO DA APRENDIZAGEM ASSENTE NA EQUIDADE E NA QUALIDADE SOCIAL}

Como sustentámos, em Portugal, a avaliação da aprendizagem tem vindo a ser perspetivada, quer nos discursos políticos e diplomas legais, quer nos discursos académicos, como um dispositivo potenciador da aprendizagem, concretizada em processos que lhe conferem um sentido formativo. Também, como foi evidenciado neste texto, esse sentido formativo da avaliação foi sempre acompanhado de outras orientações que colocam a tónica na melhoria da qualidade da educação escolar e na excelência académica traduzida em bons resultados nas provas de aferição de conhecimentos realizadas a nível nacional. Encaixada nesta lógica dilemática, a tendência, na prática, tem sido a de sobrevalorizar esta última orientação, na qual o recurso aos testes assume a forma privilegiada de avaliação e um meio propedêutico para a preparação das provas dos exames nacionais (MARINHO; LEITE; FERNANDES, 2013).

Pese embora o facto de a literatura apontar para uma certa coerência entre as conceções dos professores e as práticas de avaliação (BARREIRA; PINTO, 2005), há que reconhecer que as determinações legais podem conduzir a situações de colisão com os princípios e conceções de avaliação dos professores, sobretudo quando estes lecionam em anos de escolaridade sujeitos a exames nacionais. Esta realidade, sabemo-lo também, afasta os professores de práticas de avaliação formativa e pode, ainda que de forma não consciencializada, colocar muitos alunos em situação de maior fragilidade levando-os a experienciar sentimentos de penalização face aos processos avaliativos. 
A propósito da componente classificatória da avaliação (PERRENOUD, 1999) ou da avaliação como medida (GUBA; LINCOLN, 1989, 2000) tem sido sustentado que esta tem como principal efeito hierarquizar os alunos dentro dos grupos, isto é, fortalece, e até legitima, distinções sociais existentes e que se afastam dos princípios de equidade. De facto, o processo de classificação das aprendizagens dos alunos pode, para aqueles que se situam no grupo dos valores da escala negativos, constituir uma dupla penalização pela afixação pública da nota numa pauta hierarquizada (ESTEVÃO, 2004). A concordar com esta visão estamos a reconhecer que a avaliação pode contribuir para agravar situações de exclusão escolar e, assim, gerar o efeito de desviar os alunos da escola e dos benefícios que esta lhe poderia vir a proporcionar do ponto de vista das aprendizagens e das vivências sociais. Em extremo, estamos a considerar que os processos de avaliação, no modo como são concretizados, podem produzir situações de exclusão social. Neste raciocínio estamos a aderir à ideia de que o recurso predominante a práticas de avaliação focadas apenas na dimensão classificatória e na medida dos conhecimentos adquiridos representa uma grande limitação nos processos de ensino-aprendizagem dos alunos deixando de parte elementos de processo que constituem âncoras para aprendizagens mais significativas e que viabilizam uma educação de qualidade social (MOROSINI, 2006; DIAS SOBRINHO, 2012).

$\mathrm{Na}$ linha das ideias aqui explicitadas, postulamos que a avaliação constitua uma componente integrada do currículo, e uma prática contínua que acompanha todo o processo de ensino-aprendizagem, contribuindo, desse modo, para a regulação e a melhoria das aprendizagens. Como sugere Boggino (2009, p. 79), são os elementos de processo que "permitem aos professores oferecer aos seus alunos um apoio pedagógico sistemático e ajustado às suas possibilidades de aprendizagem" e que garanta progressos dessas aprendizagens. Em concordância com este autor, a tese que sustentamos é a de que a avaliação pode constituir uma possibilidade para promover uma educação de qualidade social porque apoia processos de ensino-aprendizagem adequados às especificidades dos diversos alunos e promove o envolvimento dos alunos em reflexões sobre os percursos que vão realizando. É este procedimento que é defendido quando se aponta para a importância das aprendizagens significativas e que propiciam o desenvolvimento de todos os alunos. Nesta perspetiva estamos a admitir também que a avaliação pode contribuir para conferir maior equidade aos processos educacionais, desde que seja realizada numa lógica de coresponsabilização, e de auto e hétero-regulação dos estudantes pela sua formação, isto é, aproximando-se do que designamos por uma avaliação formadora (LEITE; FERNANDES, 
2002). Em síntese o sentido de equidade que advogamos subentende a partilha de poder (PERRENOUD, 1999) da avaliação entre professores e alunos e reabilita a avaliação (BLACK; WILIAM, 2006) enquanto meio promotor de uma qualidade que concretiza a justiça social (CONNELL, 1997).

No quadro do paradigma de aprendizagem proclamado pelo Processo de Bolonha, isto significa que professores e estudantes têm um papel central nos processos de fromação, entendendo os primeiros como estimuladores de aprendizagens significativas e os segundos como participantes ativos, e autónomos, na construção dessas aprendizagens. Dar voz aos alunos, sobretudos àqueles que se sentem injustiçados é um argumento que precisa de deixar de ser silenciado nas escolas (SANTOS GUERRA, 2009) e nas universidades. Significa, por outro lado, que se preste maior atenção aos climas institucionais e de aprendizagem e aos modos de trabalho pedagógicos adotados, rompendo com hábitos e rotinas conservadoras e centradas na figura do professor (FERNANDES, 2011).

Reconhecemos, nesta aceção, que o envolvimento dos estudantes nas aprendizagens não se concretiza sem a criação de condições por parte dos professores que os estimulem a interagir com os seus pares, e com eles próprios, e a refletirem sobre os conteúdos que estão a ser trabalhados, e os instigue a problematizar as situações e a sobre elas emitirem um pensamento crítico (FERNANDES, 2011). A atenção a estes aspetos pressupõe criar possibilidade para que todos possam ter as mesmas igualdades de oportunidades, e se concretize o princípio de equidade, aqui entendido como respeito pelas diferenças (LEITE, 1997, 2002b; AZEVEDO, 2013). Este é, em tempo de crise económica" e de globalização da educação, um enorme desafio para os professores de todos os níveis de ensino e, de modo particular, para os que lecionam no ensino superior.

\section{REFERÊNCIAS}

ABRANTES, P.. A avaliação das aprendizagens no ensino básico. In: ABRANTES, P.; ARAÚJO, F. (Coords.). Avaliação das aprendizagens, das concepções às práticas. Lisboa: $\mathrm{DEB} \mathrm{ME}, 2002$. p. 8-15.

AFONSO, A. Políticas educativas e avaliação educacional. Braga: Instituto de Educação e Psicologia - Centro de Estudos em Educação Psicológica, 1998.

ALVES, M. P. Currículo e avaliação: uma perspectiva integrada. Porto: Porto Editora, 2004. 
ALONSO, L. Integração currículo-avaliação: que significados? Que constrangimentos? Que implicações?. In: ABRANTES, P.; ARAÚJO, F. (Coords.). Avaliação das aprendizagens, das concepções às práticas. Lisboa: DEB ME, 2002. p. 18-23.

ALTABACH, Philip G. Knowledge and education as international commodities: the colapse of common good. International Higher Education, n. 28, p. 55-60, 2002.

AMARAL, A. et al. O ensino superior pela mão da economia. Matosinhos: CIPES/Fundação das Universidades Portuguesas, 2002.

AZEVEDO, M. Igualdade e equidade: qual é a medida da Justiça Social? Avaliação, Campinas; Sorocaba, SP, v. 18, n. 1, p. 129-150, 2013.

BARREIRA, C.; PINTO, J. A. Investigação em Portugal sobre avaliação das aprendizagens dos alunos (1990-2005). Investigar em Ciências da Educação, Lisboa, n. 4, p. 23-105, 2005.

BLACK, P.; WILIAM, D. The reliability of assessments. In.: GARDNER, John (Ed.). Assessment and Learning. London: Sage, 2006. p. 81-100.

BOGGINO, N. A avaliação como estratégia de ensino: Avaliar processos e resultados. Sísifo, Lisboa, n. 9, p. 79-86, maio/ago. 2009.

COMMISSION OF THE EUROPEAN COMMUNITIES. White Paper. European Transport policy for 2010. Time to decide. Brussels, 2001. CONNELL, R. Escuelas y justicia social. Madrid: Edições Morata, 1997. CORTESÃO, L. Avaliação formativa, que desafios? Porto: Edições Asa, 1993.

Formas de ensinar, formas de avaliar, breve análise de práticas correntes de avaliação. In: ABRANTES, P.; ARAÚJO, F. (Coords.). Avaliação das aprendizagens, das concepções às práticas. Lisboa: $\mathrm{DEB}$ ME, 2002. p. 35-42.

CUNHA, A. A avaliação da aprendizagem dos alunos do ensino básico: análise comentada do despacho Normativo $n^{\circ}$ 30/2001. Porto: Edições ASA, 2001. 
DIAS SOBRINHO, J. Políticas y conceptos de calidad: dilemas y retos. Avaliação, Campinas, Sorocaba, SP, v.17, n. 3, p. 601-618, 2012.

DOURADO, L. F.; OLIVEIRA, J. F. A qualidade da educação: perspectivas e desafios. Caderno CEDES, Campinas, v. 29, n. 78, p. 201-215, 2009.

ESTEVÃO, C. V. Educação, justiça e autonomia. Os lugares da escola o bem educativo. Cadernos CRIAP, Porto, n. 43, 2004.

FERNANDES, D. Avaliação das aprendizagens: das prioridades de investigação e de formação às práticas na sala de aula. Revista de Educação, São Paulo, v. 8, p. 15-20, 1994.

. Avaliação na escola básica obrigatória: fundamentos para uma mudança de práticas. In: CUNHA, Pedro da (Ed.). Educação em debate. Lisboa: Universidade Católica, 1997. p. 275-294.

. Avaliação das aprendizagens: uma agenda, muitos desafios.

Lisboa: Texto Editores. 2004.

. Avaliação das aprendizagens: desafios às teorias, práticas e políticas. Lisboa: Texto Editores, 2005.

. Para uma teoria da avaliação formativa. Revista Portuguesa de Educação, Braga, v. 19, n. 2, p. 21-50, 2006.

. Avaliação das aprendizagens em Portugal: investigação e teoria da actividade. Sísifo, Lisboa, n. 9, p. 87-100, 2009.

FERNANDES, M. Métodos de avaliação pedagógica. In: ABRANTES, P.; ARAÚJO, F. (Coords.). Avaliação das aprendizagens, das concepções às práticas. Lisboa: DEB ME, 2002. p. 67-76.

FERNANDES, P. A avaliação da aprendizagem no ensino superior: possibilidades e limites de uma prática formativa. In: LEITE, C. (Org.). Sentidos da pedagogia no ensino superior. Porto: CIIE/Livpsic, 2010. p. 99-110.

FERNANDES, P. Pode a avaliação melhorar ou prejudicar a aprendizagem? Uma reflexão a partir do ponto de vista de um grupo de estudantes. In: LEITE, C. et al. Políticas, fundamentos e práticas do currículo. Porto: Porto Editora, 2011. p. 252-263. 
FERREIRA, C. A. Uma abordagem à avaliação das aprendizagens na formação de professores no contexto de Bolonha. Avaliação, Campinas; Sorocaba, v. 18, n. 3, p. 685-707, nov. 2013.

FIRMINO. M. Modos de trabalho pedagógico e de avaliação da aprendizagem no ensino superior: um estudo na Universidade do Porto. 2013. Tese (Doutorado) - FPCEUP, Porto, Portugal.

FIRMINO, M.; LEITE, C. Assessment of and for learning in higher education: from the traditional summative assessment to the more emancipatory formative and educative assessment. Transnational Curriculum Inquiry, 2014 (no prelo).

GUBA, E. G.; LINCOLN, Y. L. Fourth generation of evaluation. San Francisco: Jossey Bass, 1989.

GUBA, E.; LINCOLN, Y. Paradigmatic controversies: contradictions and emerging confluences. In: DENZIN, N.; LINCOLN, Y. (Eds.). Handbook of qualitative research. 2. ed. Thousand Oaks: Sage, 2000.

LEITE, C. As palavras mais do que os actos? O multiculturalismo no currículo e no sistema educativo português. Tese (Doutorado). Porto: FPCEUP, 1997.

LEITE, C. O currículo e o multiculturalismo no sistema educativo português. Lisboa: Gulbenkian/FCT, 2002b.

LEITE, C. Um olhar curricular sobre a avaliação. In: LEITE, C. Avaliar a avaliação. Porto: Edições Asa, 2001. p. 7-23.

. Processos avaliativos e suas interfaces com a didática universitária em contextos de complexidade. In: LEITE, C.; ZABALZA, M. (Coords.). Ensino superior: inovação e qualidade na docência. Porto: CIIE, 2012. p. 907-918.

Avaliação e projectos curriculares de escola e/ou de turma. In: ABRANTES, P.; ARAÚJO, F. (Coords.). Avaliação das aprendizagens, das concepções às práticas. Lisboa: DEB ME, 2002a. p. 45-55.

LEITE, C.; FERNANDES, P. A avaliação das aprendizagens dos alunos: novos contextos, novas práticas. Porto: Edições Asa, 2002. 
. A avaliação dos alunos no ensino básico e a retórica de uma consulta pública: uma primeira reflexão. Correio da Educação, n. 201, p. $1-4,2004$.

LIMA, L. Patterns of institutional management: democratisation, autonomy and the managerialist canon. In: NEAVE, Guy; AMARAL, A. (Eds.). Higher education in Portugal 1974-2009: a nation, a generation. Porto/London: CIPES/Springer, 2012. p. 287-306.

MACHADO, F. A. A avaliação em tempo de mudança: projectos e práticas nos ensinos básico e secundário. Porto: Edições Asa, 1994.

MAGALHÃES, A. A identidade do ensino superior: política, conhecimento e educação numa época de transição. Lisboa: Fundação Calouste Gulbenkian, 2004.

MARINHO, P.; LEITE, C.; FERNANDES, P. A avalição da aprendizagem: da pluralidade de enunciações à dualidade de concepções. Estudos em Avaliação Educacional, São Paulo, v. 4, n. 55, p. 304-334, 2013.

EUROPEAN COMISSION. Estatísticas da educação a nível regional. 2013. Disponível em: $<$ http://epp.eurostat.ec.europa.eu/statistics_explained/ index.php/Education_statistics_at_regional_level/pt $>$. Acesso em: 7 mar. 2014.

MOROSINI, M. Verbetes. In: MOROSINI, Marília (Ed.). Enciclopédia de pedagogia universitária: glossário. Brasília: INEP, 2006. v. 2.

OCDE. OECD Reviews of Evaluation and Assessment in Education: Portugal. 2012. Disponível em: <www.oecd.org/edu/evalutionpolicy>. Acesso em: 2 mar. 2014.

PACHECO, J. A. A avaliação dos alunos na perspetiva da reforma. Porto: Porto Editora, 1994.

PACHECO, J. A. Critérios de avaliação na escola. In: ABRANTES, Paulo; ARAÚJO, Filomena (Coords.). Avaliação das aprendizagens, das concepções às práticas. Lisboa/DEB ME, 2002. p. 55-65.

PERALTA, M. H. Integração currículo-avaliação: que significados? Que constrangimentos? Que implicações? In: ABRANTES, P.; 
ARAÚJO, F. (Coords.). Avaliação das aprendizagens, das concepções às práticas. Lisboa: DEB ME, 2002. p. 25-33.

PERRENOUD, P. Construir competências desde a escola. Porto Alegre: Artmed, 1999.

READINGS, B. A universidade em ruínas. Coimbra: Angelus Novus, 2003.

ROBERTSON, S. L. O Processo de Bolonha da Europa torna-se global: modelo, mercado, mobilidade, força intelectual ou estratégia para a construção Estado? Revista Brasileira de Educação, Rio de Janeiro, v. 14, n. 42, p. 407-422, 2009.

SANTOS GUERRA, M. Almas tatuadas. Aprendizagens sobre avaliação a partir da experiência. Sísifo, Lisboa, n. 9, p. 101-113, maio/ago. 2009.

SANTOS, L. Autoavaliação regulada: porquê, o quê e como? In: ABRANTES, P.; ARAÚJO, F. (Coords.). Avaliação das aprendizagens, das concepções às práticas. Lisboa: DEB ME, 2002. p. $55-65$.

SANTOS, S. M. Análise comparativa dos processos europeus para a avaliação e certificação de sistemas internos de garantia da qualidade. Lisboa: A3ES, 2011.

UNESCO. Declaração Mundial sobre educação superior no século XXI. São Gonçalo: UNIVERSO, 1998. 